\title{
An agent-based simulation of cooperation in the use of irrigation systems
}

\author{
Jingjing $\mathrm{Cai}^{1}$ and Hang Xiong ${ }^{2^{*}}$
}

*Correspondence:

hxiong@ethz.ch

${ }^{2}$ Agricultural Economics

and Policy Group, ETH Zurich,

Zurich, Switzerland

Full list of author information

is available at the end of the article

\begin{abstract}
This study presents an agent-based simulation of the formation of cooperation in using irrigation. The simulation model is developed based on our understanding of the underlying mechanisms by which farmer households participate the cooperation. That is, a household first become a potential participant when the cost of cooperation it needs to sustain is not higher than the amount it can afford or is willing to pay; and on top of this, the propensity that the household participates is heavily affected by its personal characteristics and neighborhood effects. We use model to examine the impacts of initial participants and government support on both the reach and velocity of the cooperation diffusion. The model is calibrated to villages with successfully running Water User Association in central China. Our results show that government support plays a critical role but the initial participants do not matter much for different types of initial participants and network structure of the village.
\end{abstract}

Keywords: Cooperation, Water user association, Agent-based modelling, Neighborhood effects, Social networks

\section{Introduction}

Large-scale irrigation systems are central to the socio-economic development in developing countries. The systems not only support the livelihood of farmers who rely on them to water their crops, but also determine the amount of resources that the agricultural sector can generate to fuel industrial development in urban areas (Small and Svendsen 1992). In the last few decades, due to substantial investments by governments and international donors, large-scale irrigation systems have become a major source of water for a large proportion of cultivated lands in China. The huge investments in largescale irrigation system, however, have not brought about satisfactory performance in many cases. Many of the systems have failed to generate a rate of return that is at least equal to the opportunity cost of capital, and hence are economically non-viable (Cernea 1987; Ostrom et al. 1993). Yet, a more important but often neglected problem is poor operation and maintenance (Carruthers 1981; Easter 1990; Ostrom 1992). On many systems in China, irrigation managers and famers have failed to arrange an effective working order to operate the systems and to mobilize adequate resources to maintain the irrigation facilities.

An irrigation system consists of both hard infrastructure mainly including pumping stations and irrigation canals, and soft infrastructure mainly including incentive

(C) The Author(s) 2017. This article is distributed under the terms of the Creative Commons Attribution 4.0 International License (http://creativecommons.org/licenses/by/4.0/), which permits unrestricted use, distribution, and reproduction in any medium, provided you give appropriate credit to the original author(s) and the source, provide a link to the Creative Commons license, and indicate if changes were made. 
mechanism, monitoring and sanctioning mechanism and social trust in community. The establishment and successful running of an irrigation system are heavily affected by the governance mechanism and collective actions of users. They could induce the problem of over-exploitation and incomprehensible complexity. Numerous studies find that modern irrigation systems rely on the cooperation among various agents, such as the local community, (WUA), non-government organization (NGO), etc., rather than the "blackbox" policy made by a single authority (IWMI 1995; Vermillion 1997; Ostrom and Shivakoti 2002; Ostrom 1992; Meinzen-Dick 1997). Many studies confirm the possibility of social cooperation in irrigation system (Janssen and Rollins 2012; Janssen and Baggio 2016; Boyd et al. 2003; Ostrom and Gardner 1993; Bardhan 2000; Janssen and Ahn 2006). However, the further exploration is still needed in the perspective of the cooperation mechanism and its related institutional, social and cultural systems. As the existing research on irrigation governance mostly limited to the theoretical analysis, field investigation and statistical research, they didn't analyze the evolution process and influencing factors of the formation and diffusion of irrigation self-governance with the interdisciplinary research methods and tools of complexity science.

The irrigation system is a complex system. Water users are adaptive agents, who have self-awareness, intelligence and related knowledge about their environment, and can update their knowledge and adjust behavior to the change of environment (An et al. 2005). The water users are interconnected through social relationships (e.g. kinship, neighborhood). They can interact with each other on the social networks and other types of agents (e.g. WUAs). The interactions could lead to patterns at the aggregate level, e.g., cooperation in managing the irrigation system. Agent-based modelling (ABM) is a widely use approach to study the dynamics of complex systems. It retains the heterogeneity of the actors and their interactive behaviors to a large extent, and thus is capable to provide a dynamic analysis of behavior mechanism at the micro level. As a "borrowup" modeling approach, the agent-based simulation explores insights that general topdown theoretical or empirical approaches may find difficulty to achieve. Compared to general top-down theoretical model, agent-based model can incorporate the heterogeneity of individuals more effectively. This often allows researcher to delve into a lower level of the question in discussion and thus reach more insightful conclusion, especially in the cases where heterogeneity of individuals in different social networks could impose a significant impact on the result.

This study takes the ABM approach to examine the behavioral mechanism following which the cooperation in using irrigation resource form among the users. Given the inclusion of cognitive, institutional, and social processes in irrigation self-governance, it is difficult to obtain high-quality data about decision making in irrigation collective action situations to conduct statistical analysis. In an agent-based model, one can make hypotheses about the behavioral rules or mechanisms, such as social learning (learning from others in the same social group), that are not, or are only indirectly, observable, and run simulations to test these hypotheses (Conte and Paolucci 2014). It allows observing and manipulating the decision-making process based on the complex interaction between the agents in a systematic way (Poteete et al. 2010). Agent-based model has been widely used in the studies of collective action in commons dilemmas (Axelrod 1997; Duffy 2006; Deadman 1999; Deadman et al. 2000; Ostrom 1992; Agrawal et al. 
2013; Janssen and Rollins 2009). D’Aquino et al. (2003) have experimented on irrigation systems in the Senegal River Valley with agent-based modeling. Janssen and Baggio (2016) used agent-based models to compare behavioral theories on experimental data about the formulations include concepts of trust, conditional cooperation and reciprocity, social values and other-regarding preferences.

The interactions in our model take place on a social network. Network structure can have an impact on the level of cooperation in collective action situations (Gould 1993). Due to the lack of empirical data of users' social relationships, we use well-known theoretical graph to represent the real network. Widely-discussed theoretical graphs include random network, scale-free network and small-world network, etc. In the random network, each edge between a pair of nodes has a fixed probability of being present or absent. A random network can be generated by starting with a set of isolated notes and adding successive edges between them at random. Erdős-Rényi model is commonly used to generate random networks (Erdős and Rényi 1959). It assigns an equal probability for every possible edge to occur independently. Small-world networks are characterized by high clustering and shortcuts within the network. This means that for many nodes in a social network, friends of friends are friends themselves, but occasionally an agent has contacts with an agent in a very different part of the network. The combination of local clusters and occasional shortcuts generates the results that agents within such a network relates to just a few steps (Watts and Strogatz 1998). Small-world networks can be generated using Watts-Strogatz model. A scale-free network is a network whose degree distribution follows a power law, at least asymptotically. It represents the observation that there are many nodes with only a few connections, and only a few nodes with many connections. Barabási-Albert (BA) model is commonly used to generate scale-free networks. It generates random scale-free networks using a preferential attachment mechanism, which sets that the more connected a node is, the more likely it is to receive new links. Nodes with higher degree therefore are more likely to be linked to other nodes (Barabási and Albert 1999).

Very limited literation accounting for the cooperation in use of irrigation systems emerges through farmers' social interactions can be found (Ostrom and Shivakoti 2002; Janssen and Baggio 2016). We therefore conducted household surveys to facilitate our understanding of the formation mechanism. The surveys, on one hand, help us identify the important factors in the formation process and design the behavioral mechanism; on the other hand, generate data that can be used to calibrate the model. We conducted field surveys about the use of irrigation systems in Chinese villages in 2014 and 2015. The first survey was conducted in 180 villages of 14 provinces covering eastern, central and western China. Over 500 questionnaires were collected, and over 30 interviews and focus group discussions were organized. We collected comprehensive data of farmer households' socio-economic characteristics, including size, scale of production, income, household heads' number of schooling years, and data regarding households' use of the irrigation system, including distance to irrigation water, cost of participating in collective use of the irrigation system and ratio of government subsidies. The second survey focused on two cases that we found typical from the 2014 survey. Questionnaire survey was conducted in WUA of the Third Dongfeng Canal in Dangyang, Hubei, part of central China. We chose two villages from each of the upstream, midstream and downstream of 
the canal. Approximately $20 \%$ of households in each village (containing 20 households in average) answered our questionnaires. In addition, in-depth interview and focus group discussions were conducted on WUA/village leaders and well-informed farmers in WUA of Huanglin Branch in Dangyang, Hubei. Our questions were mainly on the factors influencing the irrigation cooperation (e.g. personal characteristics, government support, neighborhood influence), the role the government played (especially the ratio of subsidies on cooperation costs), the role the seed participants played, determinants of farmers' willingness to pay the cooperation costs.

\section{Research method and model design}

\section{Formation mechanism of cooperation in irrigation}

Our simulation is based on the understanding of micro-level mechanism following which users form the cooperation in using irrigation, for instance, establishing a WUA. We obtain the understanding from both related studies and our field research.

\section{Neighborhood effects}

An individual's behavior is not only influenced by the incentive of their own economic interests, for example, cost and benefit, but also influenced by other individuals in the same group. Such influences have been referred to as, among many other terms, neighborhood effects (Crane 1991). In the formation of cooperation, neighborhood effects occur in the channels of information transmission and building commonalities.

Individuals who are uncertain about the expected payoffs tend to use information from others (social comparison or imitation) instead of relying on their own information (deliberation or repetition) (Poteete et al. 2010; Janssen et al. 2015). The information transmission often takes place through communication with peers. During the communication, individuals are assumed to pool their experience regarding the various strategies they have used. In this way, all agents derive a similar map of which strategies work well. The communication may contribute to higher levels of cooperation because it enables social learning (Deadman et al. 2000; Poteete et al. 2010).

Individuals are more likely to form cooperation with those with whom they have reciprocity or have built up reputation. Equipping individuals with certain tags and symbols, several studies show that cooperation levels are enhanced when one cooperates with those carrying the same symbols (Hales 2001; Lindgren and Nordahl 1994; Riolo et al. 2001). The work on conditional cooperation (Fischbacher et al. 2001; Frey and Meier 2004) and direct reciprocity (Delton et al. 2011) explains why actors may cooperate with non-kin strangers. Many studies find that cooperation in large groups of strangers are more likely to emerge in the case that the initiator have built up a reputation (Nowak and Sigmund 1998; Lotem et al. 1999; Wedekind and Milinski 2000; Gintis et al. 2001).

Neighborhood effects are also found in our field surveys. The interview to the leaders of the WUA of the Third Dongfeng Canal show that just a few villages were involved in the association initially. When famers in other villages observed the benefit that the seed participants' obtain, such as the declined cost of water using and the improved efficiency of irrigation, they also joined the WUA. In addition, the pioneer leaders of the WUA played a key role in the course the association forms. They mobilized their family 
members, friends and other fellows that have a contact with to join by demonstrating them the potential benefits and offering assistant.

\section{Seed participants}

The few initiators, who are most of time also the earliest participants (seed participants) in the cooperation, play a critical role in forming the cooperation. These seed participants are usually those who are well educated, risk-taking and with rich social relationships. They are usually members of the village committee, but not necessary the leader of the committee. Because of their reputation in the village, their participation itself has a demonstration effect to the potential participants, who can observed their benefits. In addition, they usually actively communicate the benefits of cooperation to the non-participants and motivate them to join so as to obtain the economies of scale in the cooperation (e.g. more individuals to share the coordination cost). Seed participants are usually is the leaders of WUA. They are thus well motivated to play the roles of solving the disputes related to the cooperation and acquiring the support from the government. For instance, the initiator and also the president of the WUA of the Third Dongfeng Canal in Dangyang personally made a lot of effort to mobilizing other villagers to participate and coordinating their interests Seed participants of such help reduce non-participants' uncertainties and increase expected benefits in their decision-making, and thus increase their propensity to participate. Therefore, we believe that the personal ability and social status of seed participants and the ratio of them can affect the formation and diffusion of irrigation cooperation.

\section{Government support}

Government support is often the key that leads to households' participation decision. The hierarchical model of "institutional mechanisms" in such processes of establish cooperative organizations in China have been intensively studied. The usually practice is that the governments (usually both central and local governments involved) package their financial subsidies and other support as projects targeting different policy aims, and the villages conducting the aimed practice apply the projects (She and Chen 2011; Zhou 2005, 2012; Qu et al. 2009; Qu 2012; Chen 2013). Developing the irrigation systems is one of the governments' projects. Through this project, the governments contract out their financial subsidies to villages or farmer organizations such as WUAs to develop their irrigation systems. The villages and WUAs usually need to compete for the subsidies. Here the leaders could play an important role in acquiring. The subsidies can help the participants lower the entry threshold and reduce related costs. During our surveys, we found all the successfully running WUAs received financial support from the government, and those with "abler" leaders tend to receive more subsidies.

Figure 1 presents the framework of how the cooperation in using irrigation, usually as a WUA, can be formed in a village.

Overall, a farmer household decides to participate the cooperation when the household first perceives it is feasible to cooperate and then its propensity to cooperate is high enough. The feasibility to cooperate that a household perceives is determined on the costs that it needs to bear in order to join the cooperation and its willingness to pay the costs. The costs of cooperation are essential the interest that participates need to 


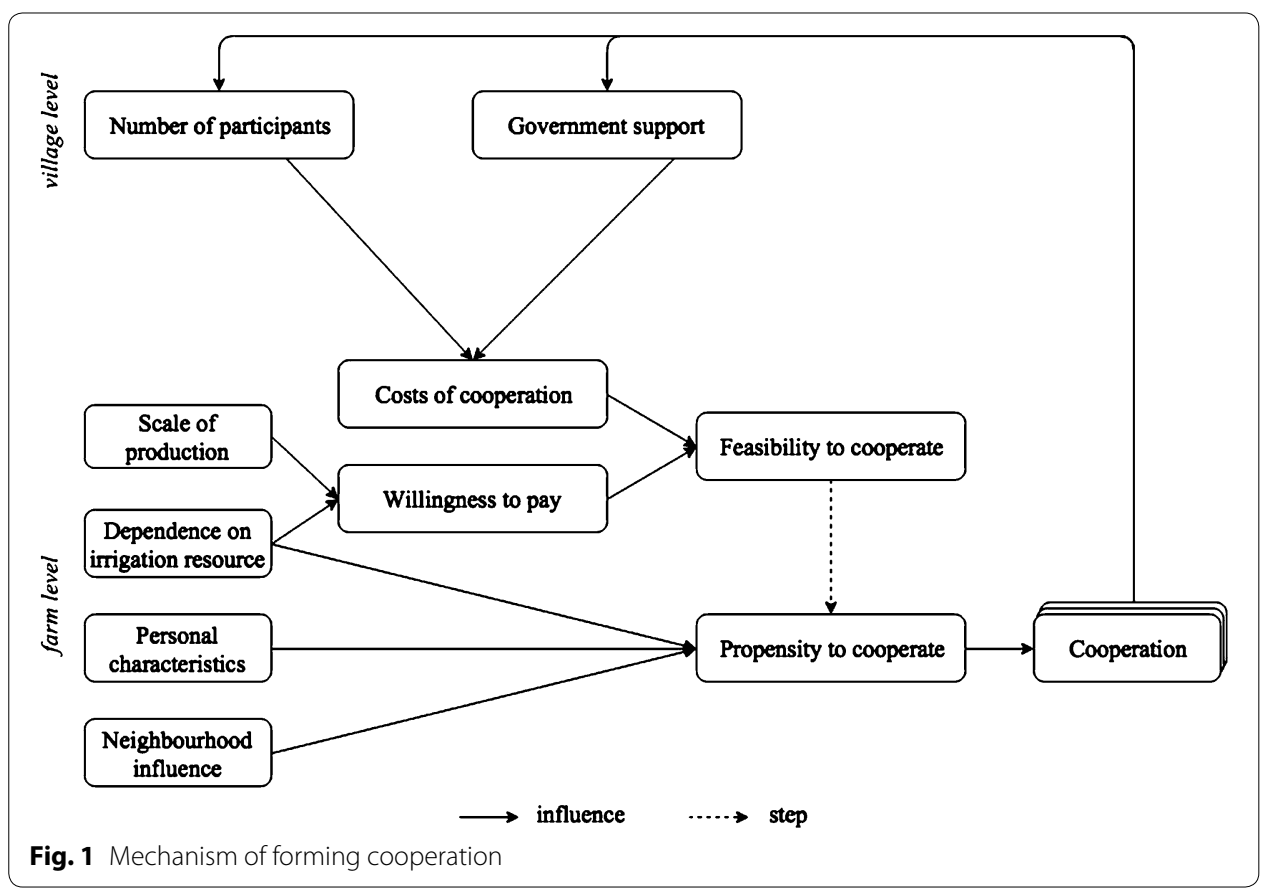

give up for the collective aim (e.g. the sustainable use of the irrigation resource) and cost of coordinating all participants. They depend on the number of participants, because the more the participants, the higher the coordination cost, and there are more participants to share the cost. Meanwhile, government support can reduce the cooperation costs by providing the financial subsidy, entitling the legal status of the WUA as nonprofit organizations and offering the management and income rights of irrigation facilities to the WUA. A household's willingness to pay the cost is essentially determined by its dependence on the irrigation resource, represented by its distance to the resource, and its scale of production that relies on the resource. A household closer to the irrigation resource generally arranges its farming in a way more reliant on irrigation and thus has stronger intention to maintain the sustainability of the irrigation. The scale of production affects a household's willingness because a small scale usually indicates that a household's income is mainly from non-farming activities (e.g. working in the cities). In general, it becomes feasible for a household to cooperate once the result of cost-benefit analysis favors cooperation; that is, the cost of cooperation is not higher than its willingness to pay.

Given it is feasible for a household to cooperate, it is more likely to cooperate when its propensity is higher. A household's propensity to cooperate is determined by its own and sometimes also the initiator's personal characteristics, the neighborhood influence it receives, and its dependence on the irrigation resource. A farmer with higher preference of risk-taking (i.e. entrepreneurship), education and incomes is generally more likely to accept a new way of using the irrigation. Nontrivially, those have high degree of social relationship and high entrepreneurship in a village usually act as the role of "initiator" in the process of forming cooperation. They have stronger mobilization ability and can reduce the cost of enforcing a new rule through their charisma and social capital. 
Neighborhood effects come through several channels. First, the potential participants use the information of cooperation benefits from earlier participants to update their cooperation decision. If only a few agents are expected to get their payoff of cooperation (cooperate at a low level), most of the agents will not cooperate. But if the expected level of cooperation is relatively high, then more and more agents will cooperate (i.e. conditional cooperation and direct reciprocity). Second, households could face the pressure coming from two aspects: (1) Group identity. If many households have joint in the WUA, the non-participants might feel being isolated or raise the concern of being considered asocial. Such lack of group identity will make one to cooperate if he observes or expects his neighbors cooperate; (2) Collective decision. If a high proportion, e.g., as two-thirds, of the village have already cooperated, the collective decision could become a regulation that all villagers must obey. Meanwhile, the strong ego-involvement as a form of social norms will also nudge the cooperation among the individuals. Third, the initiator or earlier participant usually first choose to mobilize those people who are similar to them and trust them, i.e. agents carrying the trustworthy symbols.

Based on the above presented behavioral mechanism, we developed an agent-based model to simulate the formation of cooperation in the use of irrigation system in a village. Below we describe our model employing the ODD protocol. Using this model, we will test the following hypotheses:

Hypothesis 1 The velocity that households joint the cooperation is positively associated with the proportion of seed participants.

Hypothesis 2 Both the velocity that households joint the cooperation and the coverage of the cooperation are positively associated with the governmental subsidies.

\section{The ODD protocol model description}

\section{Purpose}

The purpose of the model is to understand how cooperation in managing an irrigation resource is formed among autonomous individuals, e.g., farmers in the same villages. The initial way of managing irrigation individually is not sustainable. To avoid "tragedy of the commons" (Hardin 1968), a small portion of individuals, e.g., those who have high concern about the sustainability, propose to manage the irrigation resource cooperatively. That is, for instance, all users limit the amount they use to a certain level. Equivalently, every individual needs to give up a certain amount of its well-being. In the model, this is represented by that an individual needs to pay a fee to join the cooperation.

\section{Entities, state variables and scales}

The model comprises four types of entities: social system, irrigation resource, user (also owners) of the irrigation resource and government.

Social system is the environment where agents' (i.e., the users of the irrigation resource) collective actions of using an irrigation resource take place. Specifically, it is a village with farmer households collectively owning an irrigation resource. To represent the social relationships between farmers, the village is simulated as a social network, 
wherein nodes represent households and ties represent relationship ties between households. In this model, the social network is set either a random network or a scale-free network. Random network is generated according to Erdős-Rényi (ER) model; that is, each tie has a fixed probability of being present (Prob-ER), independently of the other ties. Scale-free network is generated according to Barabási-Albert (BA) model and using a preferential attachment mechanism. In the generation of scale-free network, the initial number of nodes is SF-initial and the probability of rewiring ties is SF-rewire.

Irrigation resource is a sum of the water and related irrigation infrastructure that households collectively own in a village. At the initial time, the irrigation resource is used in a way that all households take maximum amount of water they want. Realizing this is not sustainable, some households start to set a restriction on the amount they can take so that the use of the irrigation resource is sustainable for the village. That is, they adopt a new practice of cooperation in using the irrigation resource.

Users of the irrigation resource in a village are all the farmer households in this village. The households are connected with each other through social networks. Each household has three attributes: scale of production, entrepreneurship, dependence on the irrigation resource. Scale of production determines the amount of water that a household demands - the larger the scale, the higher the demand. It, along with the dependence on the irrigation resource, also determines the amount of the fee that a household is willing to pay in order to join the cooperation of using the irrigation resource sustainably. We assume that the distribution of scale of production among the households in a village follows normal distribution in the model. The coefficients of the normal distribution are calibrated according the features of amount of land that a household manages in the empirical data. Entrepreneurship is a synthesis of an individual's personal characteristics such as risk preference, education, leadership ability that reflect the innovativeness of a household. We assume that the distribution of entrepreneurship among the households follows normal distribution in the model. The coefficients of the normal distribution are calibrated according the features of the schooling years of a household's head in the empirical data. A household's dependence of irrigation resource is represented as the distance to the irrigation source in the social system (the artificial world in the model). The closer a household is located to the resource, the higher its dependence on the resource.

A fewer farmers are also the members of local government. They are generally those with both high entrepreneurship and high high degree (number of ties with other households) in the social network. These farmers can help obtain support from the government. The participation of these farmers can lead to the increase of the subsidies that government provides.

Government in the model is the entity that can provide subsidies to the households that participate the cooperation and directly reduce the cost of coordinating the cooperation (i.e., coordination cost).

\section{Process overview and scheduling}

In the initial period, a small portion of households in the village are set to participate in the cooperation. These households are called seed participants. The value of the portion 
is denoted by seed_ration. The seed participants are either those who with highest dependence on the irrigation resource (i.e., closest to the resource), highest degree, or highest entrepreneurship.

In the iteration periods, each non-participating household first checks if the fee it needs to pay in order to join the cooperation, i.e., cooperation fee (denoted by coop fee) is within the limit that it is willing to pay (denoted by pay_willingness). Cooperation fee is equal to the difference between coordination cost and government subsidy divided by the number of users that have participated in the cooperation, given by

$$
\text { coop_fee }=\frac{\text { coor_cost } \cdot(1-\text { subsidy_ratio })}{\text { num_part }}
$$

The coordination cost is represented as an exponential function of the number of participants, given by

$$
\text { coor_cost }=\text { num_part }{ }^{\gamma}
$$

where $\gamma$ is the coefficient of coordination cost (an exogenous variable). A household's willingness to pay for cooperation is determined by its scale of production and dependence on the irrigation resource, given by

$$
\text { pay_willingness }=\beta \cdot \frac{\text { scale }}{\text { dist }}
$$

where $\beta$ is the coefficient of cooperation expenditure (an exogenous variable), scale is the scale of family assets, following the normal distribution randomly in the whole group.

Then, each non-participant who is willing to pay more than the cooperation fee will participate with the probability of its cooperation propensity (prob_coop). Cooperation propensity is determined by a household's distance to the irrigation resource (dist), personal characteristics represented by entrepreneurship (entr), and importantly, the number of neighbors who have already participated, given by

$$
\text { prop_part }=\alpha \cdot \text { entr } \cdot \frac{\text { part_neib }+1}{\text { dist }}
$$

where $\alpha$ is the exogenously given coefficient of cooperation propensity.

Figure 2 presents the behavioral flow of non-participants at each irritation period.

At the end of each iteration, the number of participant's updates. Accordingly, coordination cost and cooperation fee are updated.

\section{Design concepts}

Emergence Emergent effects that could be observed as outcomes of the model are households' collective action of using their irrigation resource cooperatively. Opposite to using the irrigation resource individually, the collective action is an approach of sustainable use of the resource. The collective action is the outcome of households' participation in the cooperative use of the irrigation resource. The collective action might not be achieved because too few households participate the cooperation. 


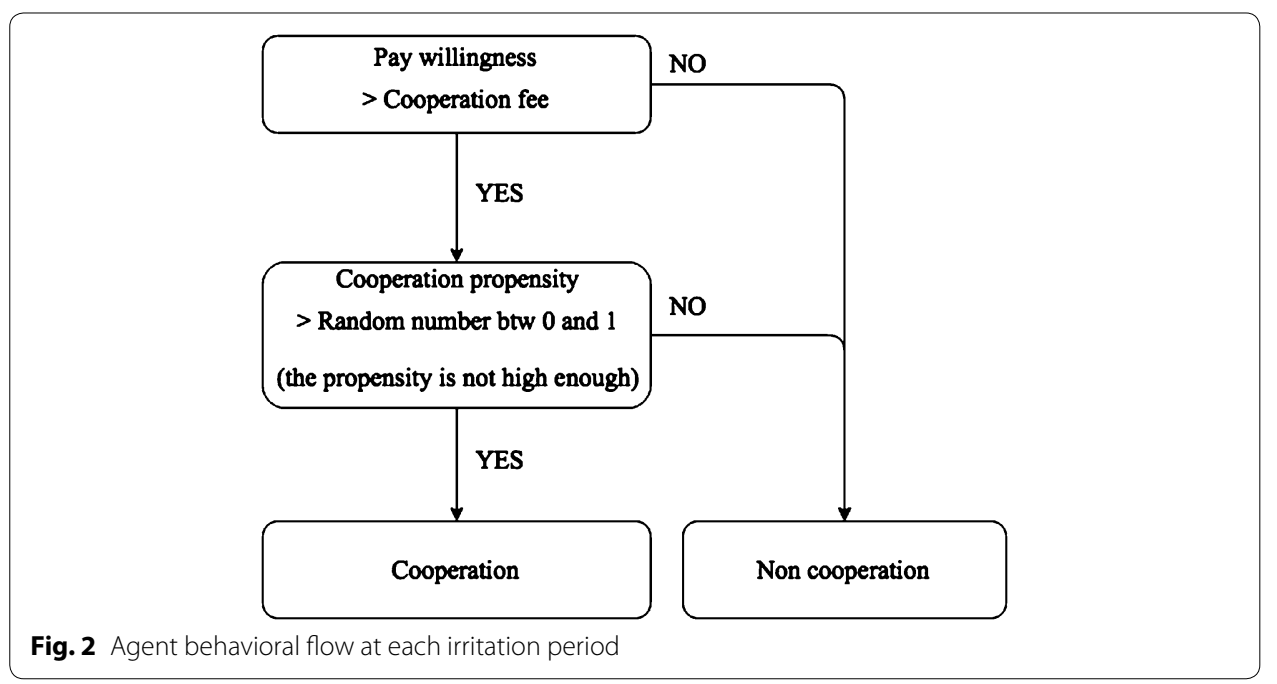

Adaptation In each iteration, each non-participating household updates their decision to participate the cooperation or not based on cooperation fee it needs to pay and the number of neighbors that have already participated.

Learning There is no learning mechanism implemented in the model.

Objectives Households and government do not have explicit objectives in the model. Households have an implicit objective of maximizing their benefits of using the irrigation resource. This is implemented through deciding whether to participate the cooperation or not.

Prediction Households in the model do not predict.

Sensing Households are aware of which households have participated in the cooperation in their village.

Interaction Households updates their propensity to participate the cooperation according to the number of their neighbors that have already participated.

Stochasticity Households are distributed in the villages and their locations ( $\mathrm{x}$ and $\mathrm{y}$ coordination in the artificial world) are set following normal distribution. Their distances to the irrigation resource and thus dependence on the resource are also random. In addition, households' other characteristics, scale of production and entrepreneurship, are assigned following the normal distribution.

Collectives All households in the model belong to a village and on the social network of the villages. No other kinds of collective emerge in the simulation.

Observation The model provides an observation of the diffusion of cooperation in using common resource. A curve displaying how the number of participating households 
change over time can be produced. In the case that the cooperation fails to diffuse, no participating household will be observed.

\section{Initialization}

The environment of the model is initialized by creating a network that consists of households and ties between the households, the characteristics of the households, and an irrigation resource in the network. The network is either a random network or a scalefree network. The characteristics of the households are scale of production, distance to the irrigation resource, and entrepreneurship. The initial state of the model world is set by the following variables.

The parameters in the simulation model are calibrated using the survey data as well as referring to existing studies. The principle is to set the mean according to the empirical data and give some flexibility (Table 1 ).

Input

This model does not use input from external sources.

\section{Sub-models}

This model does not include sub-models.

The model is implemented in NetLogo and is publicly available at https://www.openabm.org/model/4975/version/1. We run each parameter combination 100 times. There are 38,400 combinations in total, and the model runs each of these combinations 100 times. Finally, 3,840,000 sets of simulation results were generated.

\section{Results}

We are particularly interested in how the reach and velocity of the participation in the cooperation is shaped. They are reflected by participation rate and speed of participation, respectively. Speed of participation is defined as participation rate divided by the time ticks it takes to reach such participation rate. In this section, we first present the histogram of participation rates and speeds of participation the simulations produce to give an overall description. Then we report the impacts of ratio of seed participants and ratio of government subsidies on participation rate and speed of participation. Finally, we conduct regression analyses to test the robustness of our model.

\section{Histogram of the participation rate and speed of participation}

Figure 3 shows the participation rates our model generates are nicely scattered. The highest bar, range from 0.86 to 0.87 , indicates a density of around $13 \%$. Less than $10 \%$ of runs end up with complete participation. These results show that our simulation configurations cover various situations and our selection of the stopping point, i.e., 20 runs, adequately reflects such variety.

Figure 4 shows the speeds of participation are distributed among these simulations. The result indicates that the participation rate increases by $5 \%$ in average in approximately $65 \%$ of the simulations and increases more slowly in approximately $30 \%$ of the simulations. 


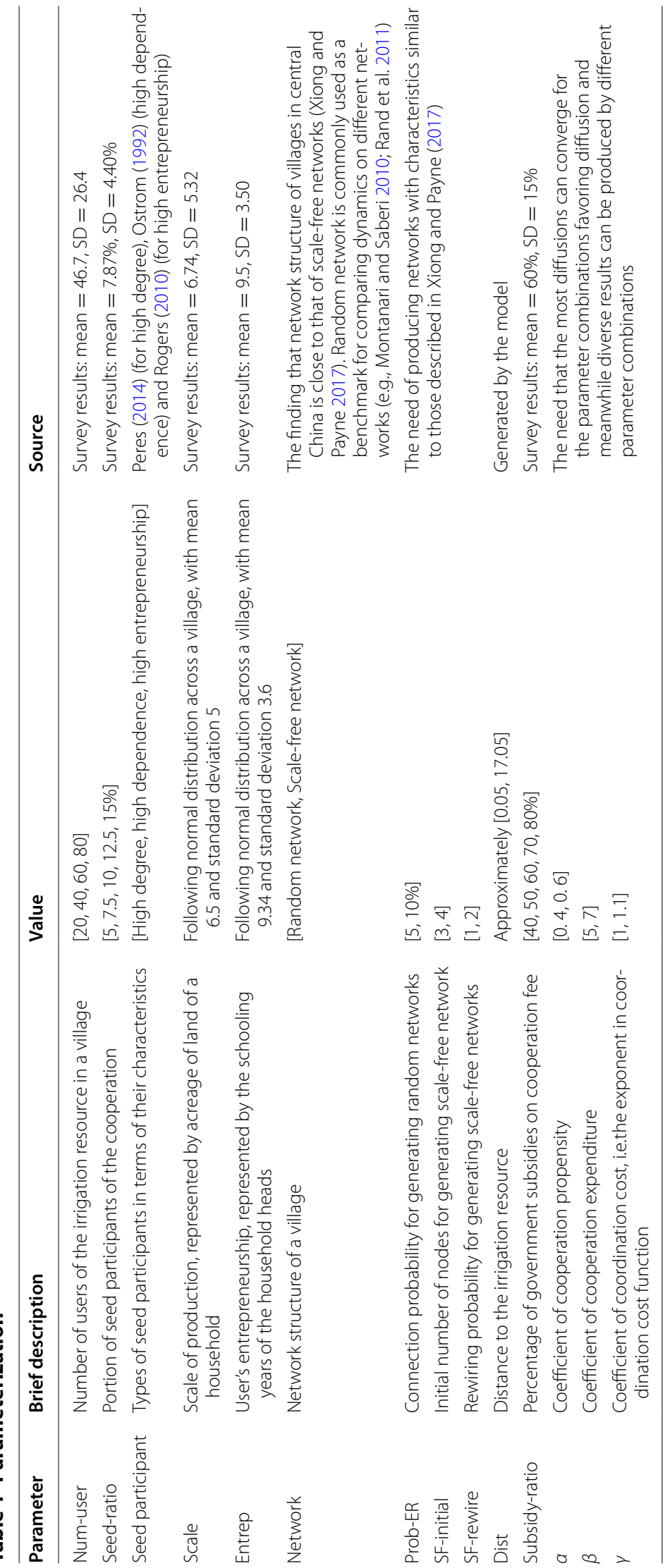



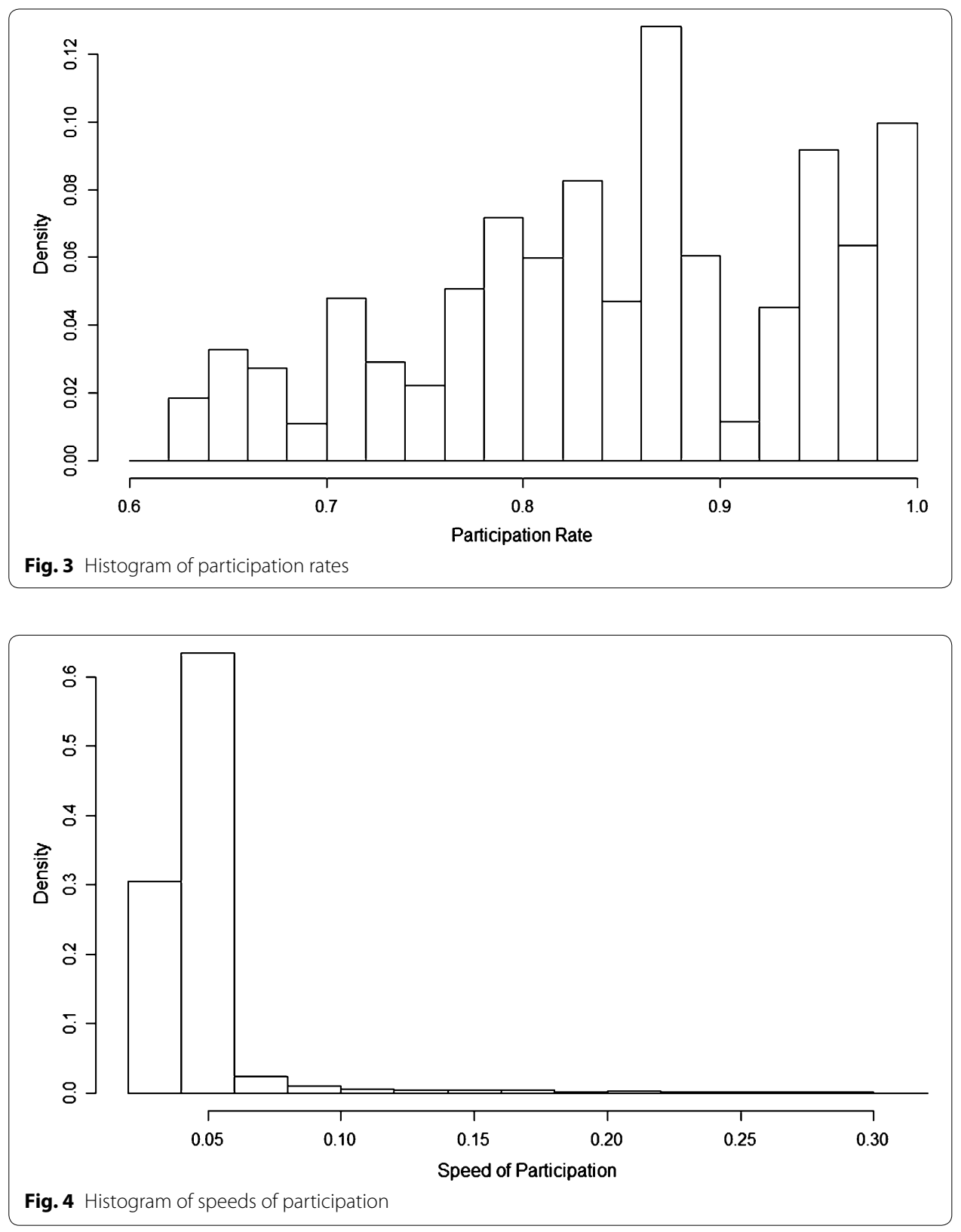

\section{Impact of ratio of seed participants}

Figures 5 and 6 present the impacts of the ratios of seed participants on participation rates and speeds of participation, respectively. Figure 5 presents plots of participation rates against the ratios of seed participants, i.e., from 6 to $14 \%$ with the interval of $2 \%$. Specifically, the three plots on the left-hand side are those for the social networks being random network and the seed participants being those with highest degree in the network, highest dependence on the irrigation resource and highest entrepreneurship, respectively. The three plots on the right-hand side are those for scale-free networks and the three types of seed participants. Our results indicate that participation rates do not vary with the ratios of seed participants in any of the six configurations ( 2 network types times 3 seed participant types). Therefore, Hypothesis 1 is not supported by our simulation results. 


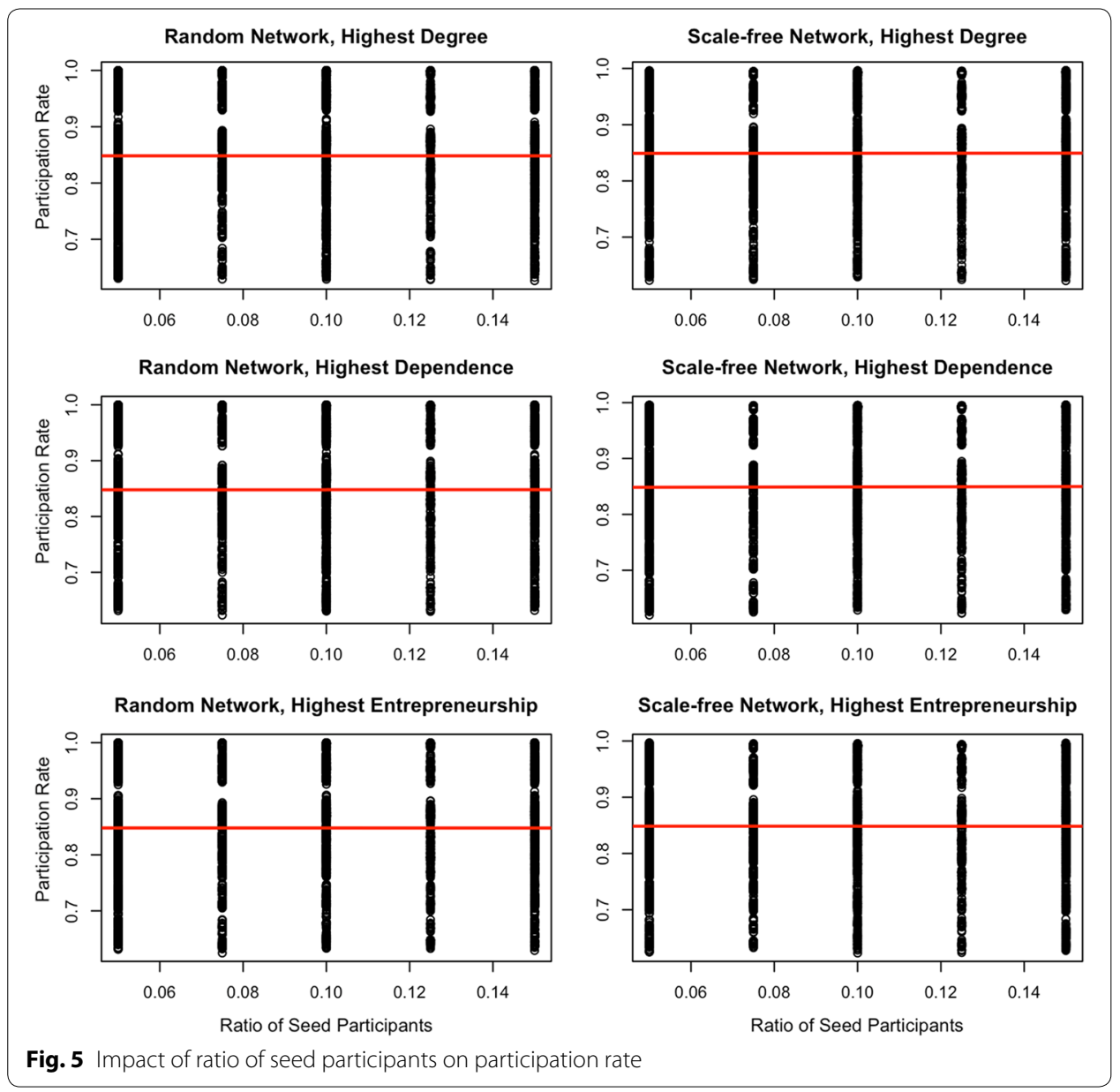

Similarly, Fig. 6 shows the plots of speeds of participation against the ratios of seed participants. The results also indicated no impact of the ratio of seed participants on the speed of participation.

\section{Impact of ratio of government subsidies}

Figures 7 and 8 present the plots of participation rates and speeds of participation against the ratios of government subsidies, respectively. Apparently, participation rates increase with the increase of ratios of government subsidies from 40 to $80 \%$ with the interval of $10 \%$. This result holds for both random networks and scale-free networks, and seed participants with the highest degree, dependence and entrepreneurship. Similar results are found for the impact of ratio government subsidies on speed of participation. The difference is that the speeds of participation are not so sensitive to the ratios of government subsidies as the participation rates are. In addition, as the ratios of government subsidies increase, the speeds of participation become more distributed, whereas the participation rates become more concentrated. These results together verify Hypothesis 2. 


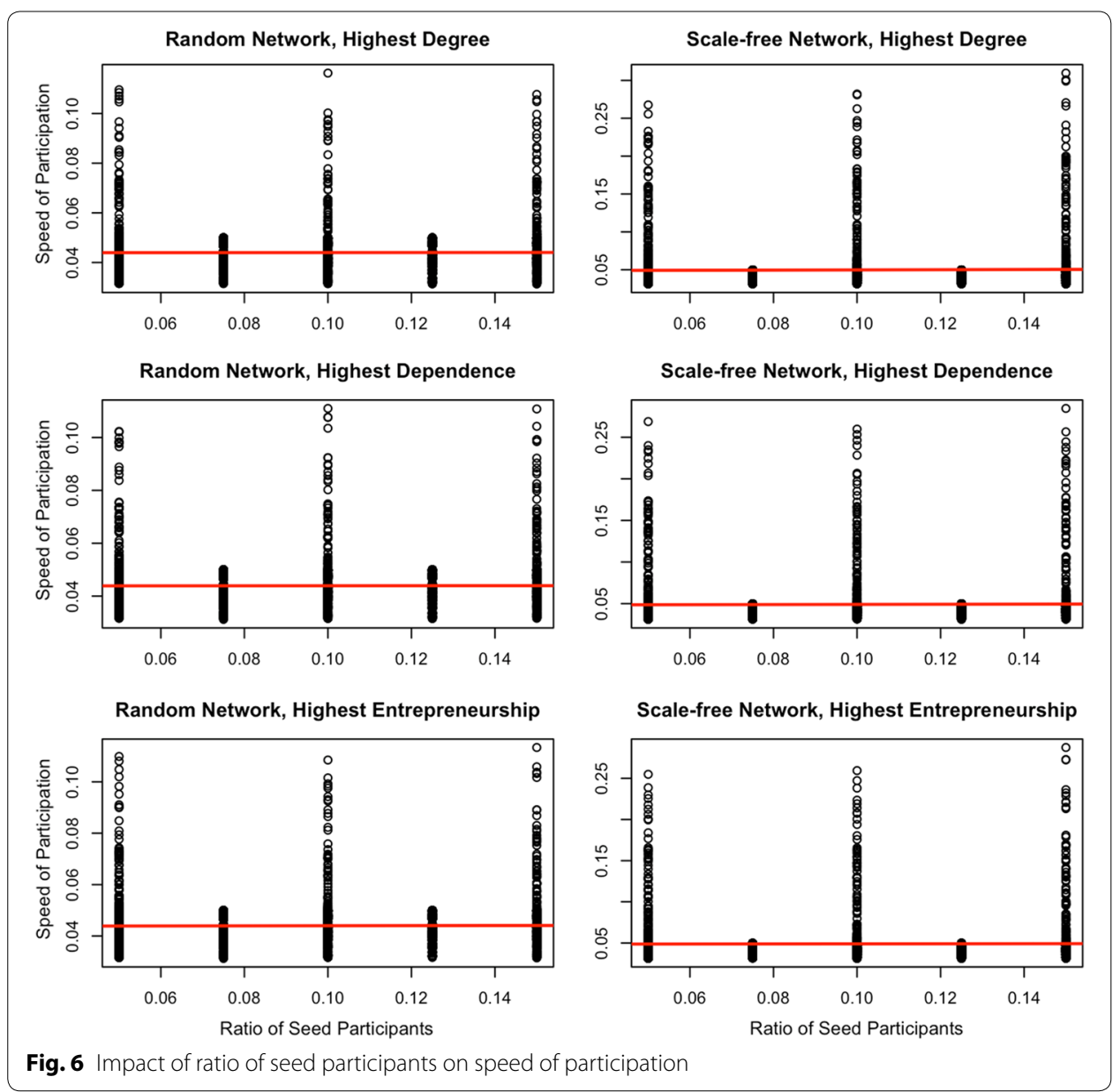

\section{Robust regression analysis}

We run regressions to test for the robustness of the model and verify the relationship between the parameters and the reach and velocity of the participation. The regressions are run using the data of obtained from all the 6400 simulations, each of which is treated as an observation. The regression equation is as below:

$$
\begin{aligned}
y= & C+\lambda_{1} \text { num_user }+\lambda_{2} \text { seed_ratio }+\lambda_{3} \text { coop_cof }+\lambda_{4} \text { spend_cof }+\lambda_{5} \text { cost_expo } \\
& +\lambda_{6} \text { subsidy_ratio }+\lambda_{7} \text { distance }+\varepsilon
\end{aligned}
$$

where $y$ is participation rate and speed of participation for the tests of reach and velocity of the participation, respectively, $C$ is the constant, $\lambda_{1}, \lambda_{2} \ldots \lambda_{7}$ are the coefficients for the seven parameters, and $\varepsilon$ is the error term.

Tables 2 and 3 present the regression results of the participation rates and the speeds of participation against the parameters. The results are grouped according to the combinations of network structures and types of seed participants.

Tables 2 and 3 that subsidy ratio has significant and positive influence on the rate and speed of cooperation diffusion for all combinations of seed participant type and network structure, but the ratio of seed participants does not have significant influence for any 


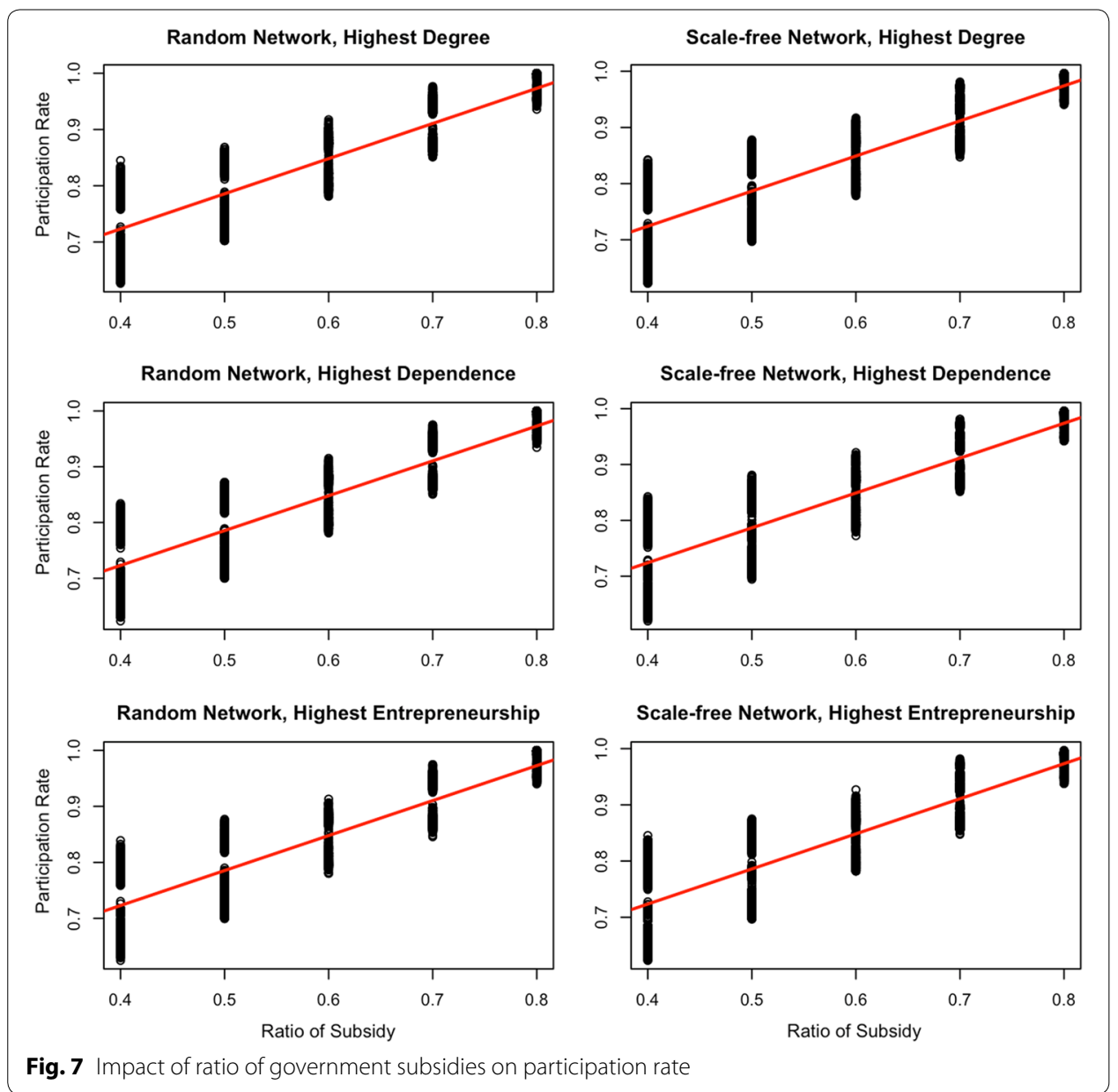

seed participant types or any network structures. These results echo the above findings of the impacts of ratio of seed participants and government support.

In addition, the regression results show that the number of users in the viallge matters in the diffusion and negatively corresponds to the rate and speed. The coefficient variables cooperation coefficient, spend coefficient and cost exponential impose significant influence on the diffusion of cooperation, and the signs are not surprising. The resource dependence, however, matters for the rate of cooperation diffusion and not entirely the case for the speed of cooperation diffusion.

\section{Discussion}

Our results highlight the critical role that government support plays in the formation of irrigation cooperation. A higher ratio of subsidies facilitates both the reach and velocity of users' participation of the cooperation. With a subsidy of more than $50 \%$ of the cooperation costs, roughly $80 \%$ of the users in a village will participate eventually. This finding is consistent with our survey results, which show that all the successful WUA receives support from local government. The support includes direct and indirect financial subsidies and the entitlement of property rights of irrigation infrastructure. It is worth noting that the financial subsidy is contradictory to the independence of the WUA even it can 


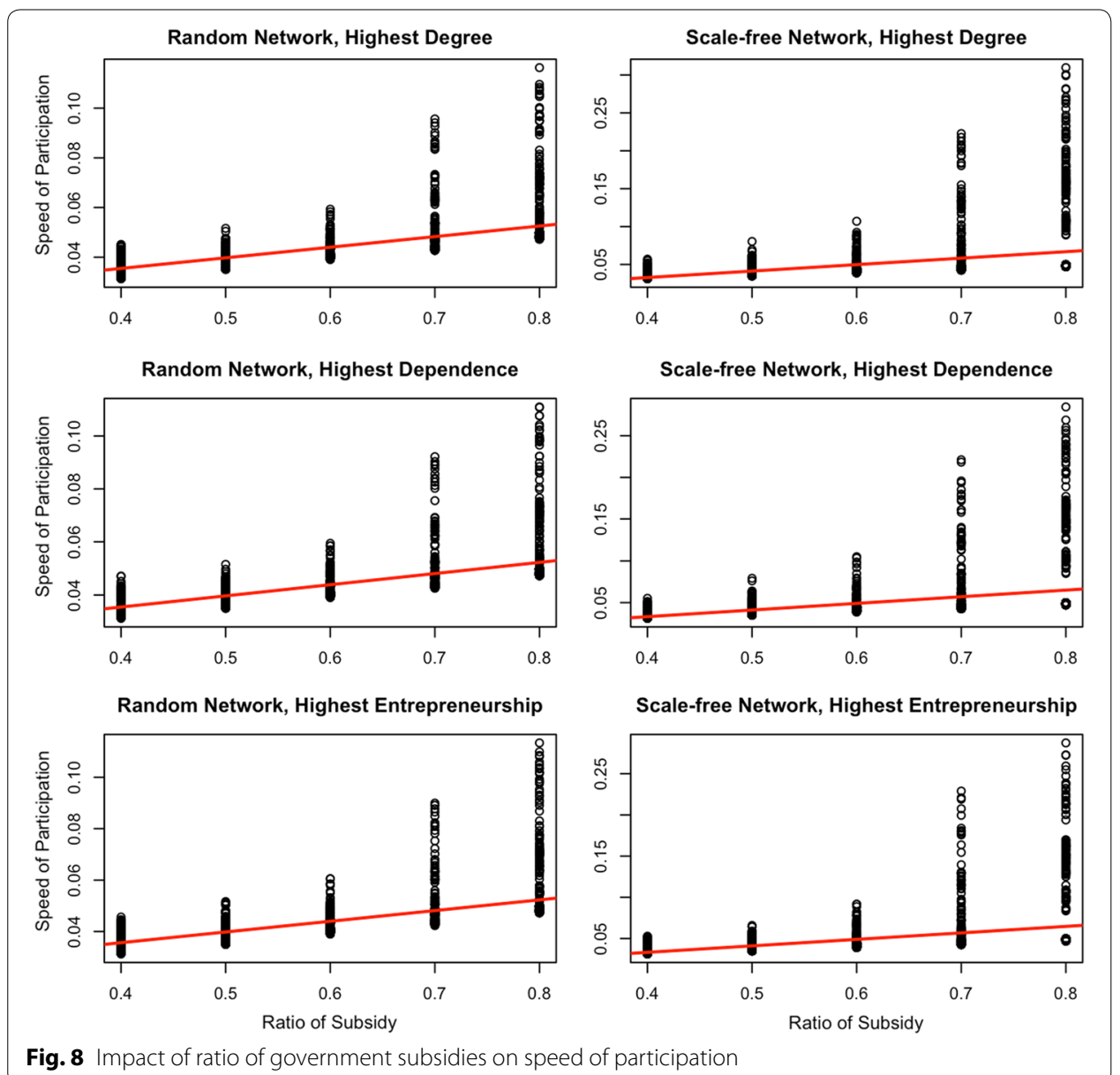

heavily facilitate the formation of cooperation. To better guarantee the performance of the WUA and its sustainable development, the government should restrict direct financial support to large irrigation facilities and focus on long-acting policies, such as technical training, providing public services and improving community-based livelihood (Cai 2012).

We did not find the ratio of seed participants matters to the cooperation diffusion. As the seed participants could be those with high entrepreneurship, high degree in social network or high dependence on irrigation, this finding do not directly support the special roles of participants with strong personal characteristics and high social status. One reason could be that neighborhood effects are relatively weaker than the influence of government support. It is thus the affordability to the cooperation costs the actual bottleneck for the households' adoption. Another reason could be that the heterogeneity among households are not high enough to demonstrate the impacts of personal characteristics and social status. For instance, dependence is a significant factor in scale-free networks, where agents' social status is highly diverse, but not significant in random networks. Such situation is also found in real world. In the cases of villages in Hubei Province, households are fairly homogeneous in terms of the dependence on irrigation, as all households make their lives by growing rice and are quite poor. The cooperation in 


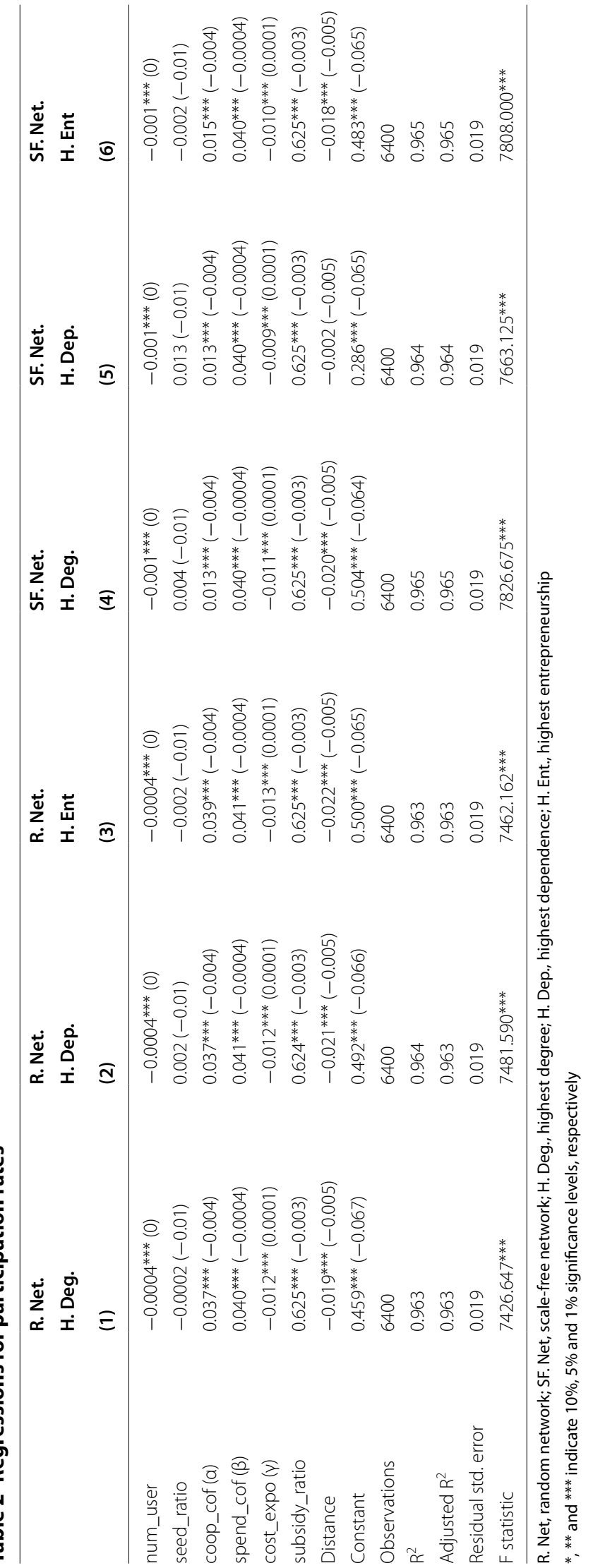




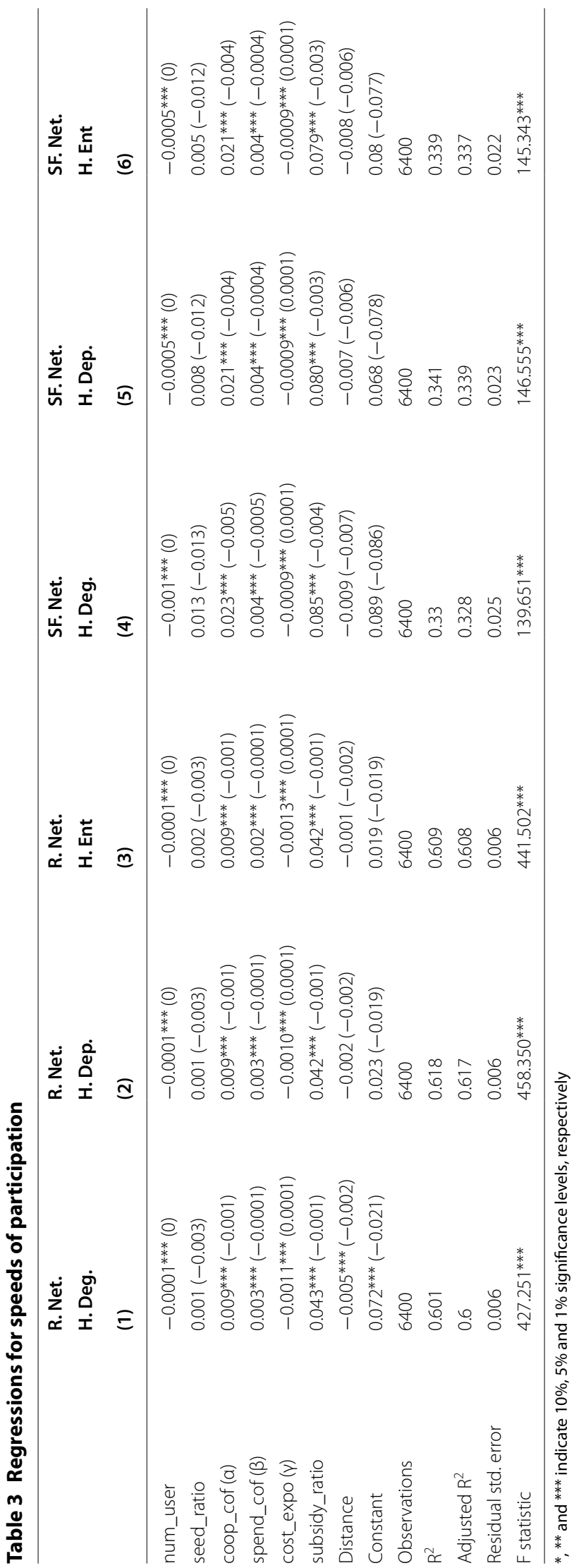


these villages shows especially high dependence on government support but much lower influence on households' socio-economic characteristics.

\section{Conclusions}

This paper discusses the underpinning mechanism following which the irrigation cooperation can form among farmer households. We present an agent-based simulation model of the cooperation formation process developed by using the mechanism. By calibrating the model to real cases in central China, we employ the model to study the impacts of seed participants and government support on the reach and velocity of users' participation in the cooperation.

By investigating the diffusion processes in the real world and reviewing existing studies, we argue that, a household would only potentially participate in an irrigation cooperation (activities or organizations) if the cost of cooperation it needs to sustain is not higher than the amount it can afford or is willing to pay. On top of this, the propensity that a household participates is heavily affected by its personal characteristics and neighborhood effects. Therefore, both the positive mechanism (social learning) and the negative mechanism (the restricting cost to be an acceptable level) shape the formation of the irrigation cooperation. The agent-based model is helpful to examining such balancing and unlinear effects.

While shared community understanding and the experience of long-term social learning are fundamental to the irrigation collective action in both day-to-day interaction and rule-crafting efforts, they by themselves are not sufficient for individuals to engage in institutional change endeavors. Individuals are willing to put time and effort into sustaining the WUA to cope with the challenge of water scarcity only if they observe that their efforts will be paid off. Based on the investigation about WUA in the real world, the willingness to pay of the individuals depends on the various social-economic status of different villages. In a village with extreme shortage of water resources, the individuals' cooperation efforts could not get the expected payoff due to the poor irrigation infrastructure whose repair needs to spend huge sums of money. As a non-profit self-organization, the WUA usually faces the financial challenge. Thus the government support plays a key role in the diffusion of irrigation cooperation.

However, only the fiscal subsidy by the government may easily lead to excessive dependence on the government. And the top-down initiated projects by governments and international donor agencies have sometimes decreased the performance of irrigation systems (Baker 2005; Shivakoti et al. 2005). It is therefore important to understand (self)-governance of irrigation systems in order to analyze potential perverse effects of interventions (Ostrom 1992; Tang 1992). In this context, the entitlement of property rights of irrigation system to the WUA and the clear definition of WUA's legal status will be fundamental to the sustainability of the WUA. As the strategy recommended in the World Development Report 1994, giving "users and other stakeholders a strong voice and real responsibility" (World Bank 1994) may enhance the economic benefits of investments in small-to-medium sized projects that intend to build social capital.

Meanwhile, when we make the prediction of successful diffusion of irrigation cooperation and its time of emergence, the topological structure of social networks, where the cooperation happens, should be concerned. Given different control variables, the 
resource dependence made different effects on the participation ratio and diffusion velocity of irrigation cooperation. Except for the village that appears as scale free network with the seed participants of high resource dependence, those highly depend on the irrigation resource should be motivated to cooperation. And in the village which appears as random network with seed participants of high degree of social relationship, those highly depend on the irrigation resource should also be encouraged to accelerate the cooperation diffusion. This finding, to some extent, validates Prof. Ostrom's point of view (Ostrom 1992) about one of the six rules that successful self-organization governance needs to be satisfied. The users of irrigation resource should be much dependent on the water resources and with a low discount rate in relation to the future benefits achieved from the resources.

Authors' contributions

JJC conceived the idea of the paper and designed the model mechanism. HX developed the simulation model. Both authors executed the simulation experiments, analyzed the simulation results and wrote the paper. Both authors read and approved the final manuscript.

\section{Authors' information}

Dr. Jingjing Cai is Associate Professor at School of Economics, Xiamen University, China. She studies the collective action and cooperation in the governance of common pool resources, focusing on the influencing factors on self-governance in irrigation.

Dr. Hang Xiong is a research associate at Agricultural Economics and Policy Group, ETH Zurich. He studies famers' collective action and how it can be shaped by social structure using computational and econometric methods.

\section{Author details}

${ }^{1}$ School of Economics, Xiamen University, Xiamen, China. ${ }^{2}$ Agricultural Economics and Policy Group, ETH Zurich, Zurich, Switzerland.

\section{Acknowledgements}

The authors would like to convey their sincere appreciation to the anonymous reviewers. Their insightful remarks and suggestions made us able to improve the quality of manuscript.

\section{Competing interests}

The authors declare that they have no competing interests.

\section{Funding}

This research is funded by the National Natural Science Foundation of China under the project "Triggering Factors and Evolutionary Mechanism of Cooperative Behaviour on Irrigation" (71303198) and the project of the National Natural Science Foundation of China "Research on Nudge Mechanism of Public Service Quality: Theory, Experiment and Application" (71603223)

\section{Publisher's Note}

Springer Nature remains neutral with regard to jurisdictional claims in published maps and institutional affiliations.

Received: 7 January 2017 Accepted: 26 July 2017

Published online: 08 August 2017

\section{References}

Agrawal A, Brown DG, Rao G, Riolo R, Robinson DT, Bommarito M (2013) Interactions between organizations and networks in common-pool resource governance. Environ Sci Policy 25:138-146

An L, Linderman M, Qi J, Shortridge A, Liu JG (2005) Exploring complexity in a human-environment system: an agentbased spatial model for multidisciplinary and multiscale integration. Ann Assoc Am Geogr 95(1):54-79

Axelrod RM (1997) The complexity of cooperation: Agent-based models of competition and collaboration. Princeton University Press, Princeton

Baker JM (2005) The Kuhls of Kangra: community-managed irrigation in the western Himalaya. University of Washington Press, Seattle

Barabási AL, Albert R (1999) Emergence of scaling in random networks. Science 286(5439):509-512

Bardhan P (2000) Irrigation and cooperation: an empirical analysis of 48 irrigation communities in South India. Econ Dev Cult Chang 48(4):847-865

Bernheim BD (1994) A theory of conformity. J Political Econ 102(5):841-877

Boyd R, Gintis H, Bowles S, Richerson PJ (2003) The evolution of altruistic punishment. Proc Natl Acad Sci 100(6):3531-3535 
Cai I (2012) Institutional analysis on the cooperation dilemma of rural water conservancy: a case study of the WUA in Fujian Q County. Issues Agric Econ 12:44-52

Carruthers I (1981) Neglect of O \& M in irrigation. The need for new sources and forms of support. Water Supply Manag 5(1):53-65

Cernea MM (1987) Farmer organizations and institution building for sustainable development. Reg Dev Dialogue $8(2): 1-24$

Chen JJ (2013) The project system and the mobilization of basic level governments: a sociological study of the projectoriented operation of social management. Soc Sci China 34(3):39-57

Conte R, Paolucci M (2014) On agent-based modeling and computational social science. Front Psychol 5:668

Crane J (1991) The epidemic theory of ghettos and neighborhood effects on dropping out and teenage childbearing. Am J Sociol 96(5):1226-1259

D'Aquino P, Le Page C, Bousquet F, Bah A (2003) Using self-designed role-playing games and a multi-agent system to empower a local decision-making process for land use management: the SelfCormas experiment in Senegal. J Artif Soc Soc Simul 6(3)

Deadman PJ (1999) Modelling individual behaviour and group performance in an intelligent agent-based simulation of the tragedy of the commons. J Environ Manag 56(3):159-172

Deadman PJ, Schlager E, Gimblett R (2000) Simulating common pool resource management experiments with adaptive agents employing alternate communication routines. J Artif Soc Soc Simul 3(2):2

Delton AW, Krasnow MM, Cosmides L, Tooby J (2011) Evolution of direct reciprocity under uncertainty can explain human generosity in one-shot encounters. Proc Natl Acad Sci 108(32):13335-13340

Duffy J (2006) Agent-based models and human subject experiments. Handb Comput Econ 2:949-1011

Easter KW (1990) Inadequate management and declining infrastructure: the critical recurring cost problem facing irrigation in Asia. Westview Press, Boulder, pp 217-245

Erdős P, Rényi A (1959) On random graphs I. Publ Math Debr 6:290-297

Fischbacher U, Gächter S, Fehr E (2001) Are people conditionally cooperative? Evidence from a public goods experiment. Econ Lett 71(3):397-404

Frey BS, Meier S (2004) Social comparisons and pro-social behavior: testing "conditional cooperation" in a field experiment. Am Econ Rev 94(5):1717-1722

Gintis H, Smith EA, Bowles S (2001) Costly signaling and cooperation. J Theor Biol 213(1):103-119

Gould RV (1993) Collective action and network structure. Am Sociol Rev 58(2):182-196

Hales D (2001) Tag-based cooperation in artificial societies. Ph.D. Thesis, Department of Computer Science, University of Essex, Essex

Hardin G (1968) The tragedy of the commons. Science 162(3859):1243-1248

International Water Management Institute (IWMI) (1995) Food and Agriculture Organization of the United Nations (FAO), irrigation management transfer. FAO, United Nations, Rome

Janssen MA, Ahn TK (2006) Learning, signaling, and social preferences in public-good games. Ecol Soc 11(2)

Janssen MA, Baggio JA (2016) Using agent-based models to compare behavioral theories on experimental data: application for irrigation games. J Environ Psychol 52:194-203

Janssen MA, Rollins ND (2012) Evolution of cooperation in asymmetric commons dilemmas. J Econ Behav Organ 81(1):220-229

Janssen MA, Anderies JM, Pérez I, David JY (2015) The effect of information in a behavioral irrigation experiment. Water Res Econ 12:14-26

Lindgren K, Nordahl MG (1994) Artificial food webs. In: Langton CG (ed) Artificial life III. Addison-Wesley, Reading, pp 73-104

Lotem A, Fishman MA, Stone L (1999) Evolution of cooperation between individuals. Nature 400(6741):226-227

Meinzen-Dick R (1997) Farmer participation in irrigation-20 years of experience and lessons for the future. Irrig Drain Syst 11(2):103-118

Montanari A, Saberi A (2010) The spread of innovations in social networks. Proc Natl Acad Sci 107(47):20196-20201

Nowak MA, Sigmund K (1998) Evolution of indirect reciprocity by image scoring. Nature 393(6685):573-577

Ostrom E (1992) Crafting institutions for self-governing irrigation systems. ICS Press, San Francisco

Ostrom E, Gardner R (1993) Coping with asymmetries in the commons: self-governing irrigation systems can work. J Econ Perspect 7(4):93-112

Ostrom E, Shivakoti G (eds) (2002) Improving irrigation governance and management in Nepal. ICS Press, San Francisco

Ostrom E, Schroeder L, Wynne S (1993) Institutional incentives and sustainable development: infrastructure policies in perspective. Westview Press, Boulder

Peres R (2014) The impact of network characteristics on the diffusion of innovations. Phys A Stat Mech Appl 402:330-343

Poteete AR, Janssen MA, Ostrom E (2010) Working together: collective action, the commons, and multiple methods in practice. Princeton University Press, Princeton

Qu JD (2012) The project system: a new form of state governance. Soc Sci China 33(4):28-47

Qu JD, Zhou FZ, Xing Y (2009) From macromanagement to micromanagement: reflections on thirty years of reform from the sociological perspective. Chinese. China Soc Sci 6:104-127

Rand DG, Arbesman S, Christakis NA (2011) Dynamic social networks promote cooperation in experiments with humans. Proc Natl Acad Sci 108(48):19193-19198

Riolo RL, Cohen MD, Axelrod R (2001) Evolution of cooperation without reciprocity. Nature 414(6862):441-443

Rogers EM (2010) Diffusion of innovations. Simon and Schuster, New York

She XY, Chen YY (2011) The mechanism and governance logic of the hierarchical operation of the project system -a sociological case study of "Projects Entering the Village". Soc Sci China 4:126-148

Shivakoti G, Vermillion D, Lam WF, Ostrom E, Pradhan U, Yoder R (eds) (2005) Asian irrigation in transition: responding to challenges. SAGE Publications India, New Delhi

Small LE, Svendsen M (1992) A framework for assessing irrigation performance. In: Working Papers on Irrigation Performance, No. 1. International Food Policy Research Institute, Washington, DC 
Tang SY (1992) Institutions and collective action: self-governance in irrigation. ICS press, San Francisco Vermillion DL (1997) Impacts of irrigation management transfer: a review of the evidence. IWMI research report 011/IIMI research report 011. International irrigation management institute (IIMI), Colombo, Sri Lanka

Watts DJ, Strogatz SH (1998) Collective dynamics of'small-world' networks. Nature 393(6684):440-442

Wedekind C, Milinski M (2000) Cooperation through image scoring in humans. Science 288(5467):850-852

World Bank (1994) World development report 1994: infrastructure for development. Oxford University Press, New York

Xiong H, Payne D (2017) Characteristics of Chinese rural networks: evidence from villages in central China. Chin J Sociol $3(1): 74-97$

Zhou XG (2005) Inverted Soft Budget Constraints: extra-budgetary Resource-seeking in Local Governments. Soc Sci China 2:132-143

Zhou XG (2012) The road to collective debt: Government Bureaucracies and public goods provision in rural China. Modern China 38(3):271-307

Submit your manuscript to a SpringerOpen ${ }^{\circ}$ journal and benefit from:

- Convenient online submission

- Rigorous peer review

- Open access: articles freely available online

- High visibility within the field

Retaining the copyright to your article

Submit your next manuscript at $\gg$ springeropen.com 